Kong. Res. J. 2(1) : 63-64, 2015

ISSN 2349-2694

Kongunadu Arts and Science College, Coimbatore.

\title{
BIOSORPTION STUDIES OF CHROMIUM AND NICKEL BY PSEUDOMONAS AND BACILLUS SP.
}

\author{
Anupriya, P., V. Jacob Vargheese and S. Saravanan Babu* \\ Department of Botany, Chikkah Naciker College, Erode. \\ *E.mail: ssbabuflora@yahoo.com
}

\begin{abstract}
In the present investigation, an attempt has been made to study the effect of biosorption of heavy metal such as Chromium and Nickel using Pseudomonas and Bacillus. The resistance of bacterial isolates to heavy metals such as chromium and Nickel has been studied. The Percentage of removal of chromium and nickel was analysed. The Percentage of removal of chromium was found using immobilization techniques. It has been found that as the concentration increases the resistance to the metal also increases. At $1000 \mathrm{ppm}$ concentration the resistance was found maximum. The uptake of chromium and Nickel was $90.7 \%$ and $80.60 \%$ by Pseudomonas respectively. Among the Pseudomonas and Bacillus, Pseudomonas proved be an efficent strain.
\end{abstract}

Keywords: Biosorption studies, chromium, nickel, Pseudomonas sp., Bacillus sp.

\section{INTRODUCTION}

The unprecedented population increase and anthropogenic activities such as industrialization and urbanization of the twentieth century in the name of modernization have not only increased conventional solid and liquid waste pollutants to critical levels but also produced wide range of previously unknown contaminants in the form of xenobiotics which are released to the environment.The persistence of toxic metals and organic pollutants in the surroundings causes pollution and deteriote the environment. Contamination of heavy metal to the environment is the major global concern because of their toxicity and threat to human life (Sharma, 2000)

The term "heavy metal" commonly refers to metals either with a specific weight higher than $5 \mathrm{~g} / \mathrm{cm} 3$ or an atomic number above 20.All of them may not be toxic at relatively low concentrations, classified as heavy metals. So,the heavy metals are a very heterogeneous group of elements, which greatly differ in their chemical properties and heterogenous group of elements, which greatly differ in their chemical properties and biological functions. For this reason, the term "Heavy metal " is discredited and terms "trace elements " are preferred by numerous authors(Phipps,1981). Heavy metals are non-biodegradable pollutants on environment and some are even hazardous to human and animals. Heavy metals in excessive quality cause toxicity and death to most living organisms. Contamination of soil and soil water results from the presence of undisturbed organisms. Contaminated soil and water results from the presence of undisturbed metal near the soil surface or from the actual mining of ores. The heavy metals are often used as fungicides, pesticides or disinfectants which are responsible for toxicity.As the metal pollutants are non degrable and are readily taken up by plants, these are likely to enter easily in to food chain (Prasad,1995).

Bio sorption is defined as a nondirected physicochemical interaction occurs between metal or radionuclide sps and microbial cells(shumate and stranberg,1985). It is a biological method of environmental control and can be an alternative to conventional contaminated water treatment facilities. A successful biosorption process required preparation of good biosorbent.The process starts with selecting various types of biosorbent. Choosing the biosorbent for metal absorption depends on origin of the adsorbents(Regin and volesky,2000). In the present study the removal of Nickel and chromium is studied using the bacterial bioadsorbents Pseudomonas and Bacillus.

\section{MATERIALS AND METHODS}

With a view to study the biosorption of Nickel and Chromium, the present study was made considering the environmental parameters which affect the update of Nickel and chromium by Bacillus and Pseudomonas .The glassware were washed thoroughly in running tap water, rinsed in distilled water and dried in a hot air oven(Yorco vertical;autoclave,Mumbai) at 121:C at $15 \mathrm{lbs}$ pressure for 15 minutes. The sample was collected in a sterile container from the heavy metal contaminated sites in and around sivakasi. The 
isolation was done by inoculating $1 \mathrm{gm}$ of soil in $100 \mathrm{ml}$ of nutrient broth. It was incubated in a shaker in 150rpm for 24 hours at 37:C.The isolated were subcultured in fresh medium and maintained at 40C. This bacterial isolates were tested to determine the resistance for heavy metals such as chromium and nickel at various concentrations. Resistance to heavy metals is determined by plane method and well method. Cells of Bacillus and Pseudomonas were harvested during the exponential phase of growth and re-suspended in 4\% sodium alginate solution. The resulting mixture was dropped in to the $\$ \%$ calcium chloride solution and incubated at 4:C for 2hours with constant and gentle stirring for complete gel formation. The immobilized beads were then transferred to fresh nutrient broth and incubated for 12 hours for further cell growth of Pseudomonas.The beads were harvested by filtration and washed with sterile distilled water. The immobilized cell beads were prepared under aseptic conditions. The beads were transferred to $100 \mathrm{ppm}$ of chromium and nickel in $100 \mathrm{ml}$ sterile distilled water in separate flasks and incubated at 30:C in a rotary shaker at $120 \mathrm{rpm}$ for 24 hours.Two controls without cell were maintained for chromium and nickel respectively. After the incubation the beads were collected and suspended in $50 \mathrm{ml}$ of $0.05 \mathrm{M}$ nitric acid with gentle stirring for $1 \mathrm{hr}$ for the desorption of metal ions. Finally the metal concentration of present in the filtrate was analysed in shimadzu AA-6300 Atomic Absortion Spectrophtometer.

\section{RESULTS AND DISCUSSION}

The following results were obtained in the comparative study of Nickel and Chromium by Bacillus and Pseudomonas. The resistance of bacterial isolates to chromium and nickel was checked qualitively by inoculating the isolates in nutrient agar plates containing various concentrations of Chromium and Nickel. It was found that as the concentration increases the growth of bacteria decreases for both Chromium and Nickel. At $500 \mathrm{ppm}$, it exhibits maximum resistance for both Chromium and Nickel. The Zone of inhibition at various concentration is determined. As the concentration increases, the zone of inhibition also increases. The isolates Pseudomonas and Bacillus Strains exhibits maximum resistance. Hence these two strains are selected for further study. Chromium and Nickel reduction by was also observed by using immobilized biobeads using calcium alginate gel.
Immobilzed biobeads were inoculated at various concentrations of nickel and chromium. After incubation the supernatent was digested with acid and analysed in AAS.

Table 1

\begin{tabular}{clcc}
\hline \multirow{2}{*}{ S.No } & \multirow{2}{*}{ Isolates } & \multicolumn{2}{c}{ Percentage of Removal } \\
\cline { 3 - 4 } & & Chromium & Nickel \\
\hline 1 & Pseudomonas & $90.70 \%$ & $80.60 \%$ \\
2 & Bacillus & $78.00 \%$ & $75.30 \%$ \\
\hline
\end{tabular}

Table 2

\begin{tabular}{clcccc}
\hline \multirow{2}{*}{ S.No } & \multirow{2}{*}{ Isolates } & \multicolumn{4}{c}{ Concentration of Chromium(mm) } \\
\cline { 3 - 6 } & & $\mathbf{2 5 0}$ & $\mathbf{5 0 0}$ & $\mathbf{7 5 0}$ & $\mathbf{1 0 0 0}$ \\
\hline 1 & Pseudomonas & 1.50 & 2 & 3 & 2.2 \\
2 & Bacillus & 1.70 & 2 & 3 & 3.2 \\
\hline
\end{tabular}

\section{ACKNOWLEDGEMENT}

The authors are greatful to the principal chikkah naicker college,Erode for providing laboratory facilities. The authors are also thankful to the Biogenic lab,Namakal.

\section{REFERENCES}

Phipps, D.A., (1981). Chemistry and Biochemistry of trace elements in biological systems. In N.W.Leep Effect of heavy metal pollution on plants. Applied science publications London 1: $1-54$.

Prasad, M.N.Y., (1995). Inhibition of maize leaf chlorophyll,carotenoids and gas exchange funcations by cal. Photosynthesis. App. Environ. Microbiol. 31: 635-640.

Regine and Volesky, (2000). Isoution and characterization of chromate resistanct bacteria from tannery effluent. J. Environ. Biol. 28(22): 399-403

Sharma., (2000). Mircobiol Bioremediation. P. Rajendran, P. Gunasekaran. MJP Pubilshers 344: 47-49.

Shumate, S.E., and G.W. Strangberg, (1985). Accumlation of metal by microbial cells in comprehensive Biotechnol. M.M. Young Pergamom Press New York. 235-247.

Sultan, S. and S. Hasnain, (2005). Chromate reduction capability of a Gram-positive bacterium isolated from effluent of dying industry. Bull. Environ. Contam. Toxicol. 75: 699-706. 